\section{Climate: open review may ease acceptance of report}

SIR - As executive director of the Office of the US Global Change Research Program from 1993 to 1997, I was responsible in 1995 for urging adoption of the national review process of the IPCC report that is questioned in your News story "US posts sensitive climate report for public comment"

(Nature 441, 6-7; 2006).

The IPCC has always used a multi-stage review process. The first review is by nominated technical experts. In the second review, however, copies of the report are also sent to governments and all nongovernmental organizations registered with the IPCC. In this round, the governments can each choose their own review process. What led to the US decision for open review was a query from one industry association that was interested in the environment but had not been sending a representative to IPCC plenary meetings. It asked why it was denied a chance to review the report when similar groups with a clear advocacy position were not. We could think of no acceptable answer. If all the world's nations and hundreds of scientists and nongovernmental groups could review the report, how could we say some groups could not?

In response, at my urging, the US government agreed to a process whereby notice of the report's availability would be published in the Federal Register, calling for comments. This has been the practice ever since, and initial fears that it would be abused, for example, by large numbers of coordinated pleadings, have not materialized.

We did insist that those submitting comments identify themselves: a step we hoped would encourage careful and responsible presentation of comments. But we decided that what would matter was the merit of the comment, not its origin. Each comment was evaluated by an interagency team of government programme managers with interests and expertise in the area under consideration. In general, most comments were accepted: industry reviewers often had special insight into issues relating to emissions and approaches to mitigation; environmentalgroup reviewers had views on ecosystem behaviour and related pollution issues; and public reviewers had views on the clarity of presentation, or the significance or uncertainty of the findings. There were some off-the-mark and gratuitous comments, but not many, and these were filtered out by the interagency review process.

My impression was that the process worked well through the second and third IPCC assessments, and that the comments submitted helped to improve the overall quality of the assessments. There were instances of a strong difference of opinion within the expert community. But in all cases, through communication between authors and reviewers, we were able to facilitate a positive outcome. There was a sense that all legitimate perspectives (those written up in peer-reviewed or other equivalent form) had been fairly considered.

I have notbeen part of the government's planning or conduct of this review round. I am impressed, however, by their commitment to continuing the open approach. Let's not fear getting comments; in my opinion, promoting wide involvement in the review process, where questions can be clarified, has much greater potential for winning general acceptance of the findings than springing results on uninformed parties through some media blitz at the end of the process.

Michael MacCracken

Climate Institute, 1785 Massachusetts Avenue

NW, Washington DC 20036, USA

\section{Climate: US has always made IPCC drafts available}

SIR — Your News story " US posts sensitive dimate report for public comment " (Nature 441, 6-7; 2006) implies that the United States has departed from its traditional approach in reviewing draft reports from the Intergovernmental Panel on Climate Change (IPCC). In fact, US procedures, first published in the Federal Register in 1995, reflect our longstanding commitment to open IPCC reviews.

Under the 1995 procedures, we provided paper copies of IPCC draft reports to any individual upon request. In 2000 , individuals were also asked to provide information on their ${ }^{\alpha}$ qualifications and general area of expertise ... to review specific parts of the report", although to the best of my knowledge drafts were made available to all who submitted requests. Since September 2004, after legal counsel advised that requiring individuals to provide such information was inconsistent with federal informationdissemination guidelines, we have made IPCC drafts available on the US Climate Change Science Program website (www.climatescience.gov/Library/ipcc); this prominently displays IPCC instructions that drafts not be cited, quoted or distributed. As far as we were aware, everyone accessing this website had abided by the IPCC instructions, until Nature published elements of the Fourth Assessment Report.

Our approach reflects the view that it is neither possible nor appropriate for the government to decide which individuals are expert enough to review the report. Comments on the draft will be reviewed on their merits by prominent scientists during both US and international IPCC reviews. To ensure objectivity, submitted comments will be supplied to federal programme managers and scientists without attribution and then evaluated on scientific and technical grounds before being sent to the IPCC.

The United States is committed to an effective review of the IPCC Fourth Assessment Report, and we intend to provide comments reflecting the extensive expertise of the US scientific community.

Harlan L. Watson

US Department of State, 2201 C Street NW, Washington DC 20520, USA

\section{HIV denialists ignore large gap in the study they cite}

SIR - Valendar Turner, in Correspondence ( ${ }^{\circ} \mathrm{HIV}$ drug remains unproven without placebo trial ${ }^{x}$ Nature 434,$137 ; 2005$ ), argues that there is no evidence for antiretrovirals reducing the transmission of HIV from mother to child. He points out that HIV transmission in people taking the antiretroviral drug nevirapine was $13.1 \%$ in the HIVNET 012 study in Uganda, whereas only $12 \%$ of women in a Rwandan study were found to have transmitted HIV to their babies in the absence of antiretroviral treatment.

Despite a rebuttal in Correspondence by the authors of the Ugandan study, Brooks Jackson and Thomas Fleming ("A drug is effective if better than a harmless control ${ }^{\text {D }}$ Nature 434, 1067; 2005), Turner's letter continues to be cited by AIDS denialists (for example, C. Farber Harper's Magazine 37-52; March 2006).

The Rwandan study referred to by Turner enrolled 561 pregnant women, of whom 286 were HIV-positive. Of the children born to HIV-positive mothers, 158 were tested for HIV and 19 (12\%, as Turner states) were found to be HIV-positive. Why were only 158 children assessed? The answer, conveniently ignored by the denialists, is that follow-up was interrupted by the events of the Rwandan civil war (J. Ladner et al. J. Acquir. Immun. Def. Syndr. Hum. Retrovirol. 18, 293-298; 1998). Given that this interruption was sufficiently lengthy for many HIV-positive children and their mothers to die of AIDS in the interim, the surviving sample of the initial cohort cannot be regarded as representative. The actual figure for HIV transmission was almost certainly much higher. Failing to acknowledge this important caveat to the study appears to us to be inconsistent with accepted academic standards.

Nathan Geffen ${ }^{\star}$, Nicoli Nattrass $\uparrow$, Glenda Gray *Treatment Action Campaign, 34 Main Road, Muizenberg 7945, South Africa

†AIDS and Society Research Unit, University of Cape Town, Private Bag, Rondebosch 7701, Cape Town, South Africa

țerinatalHIV Research Unit, University of Witwatersrand, PO Box 114, Diepkloof 1864, South Africa 